\title{
Penyusunan Basis Data Infrastruktur Sanitasi Sekolah Dasar Negeri Berbasis Website di Kecamatan Rasau Jaya
}

\author{
Reza Wahyudi $^{1 *}$, Ridho Dedy Arief Budiman², Farly Detrias ${ }^{3}$ \\ ${ }^{1}$ Program Studi Teknik Lingkungan, Universitas Nahdlatul Ulama Kalimantan Barat, Pontianak \\ ${ }^{2}$ Program Studi Pendidikan Teknologi Ilmu Komputer, IKIP PGRI Pontianak, Pontianak \\ ${ }^{3}$ Program Studi Sistem Informasi Universitas Nahdlatul Ulama Kalimantan Barat \\ *Koresponden email: rezawahyudihse49@gmail.com
}

Diterima: 5 November 2019

Disetujui: 3 Desember 2019

\begin{abstract}
The compilation of a database of public primary school sanitation infrastructure in Rasau Jaya District is based on the 2007 Minister of Education Regulation on the standards for facilities and infrastructure of public primary schools in Indonesia. Besides, this research is also an effort to support the Kubu Raya District one data program which aims to help district governments in planning district programs so that they can be implemented properly and accurately in the field of public elementary school sanitation infrastructure. In this study direct observations to the site and conduct interviews related to the availability of primary school sanitation infrastructure. The number of public elementary schools included in the research area is 18 public elementary schools spread across 6 villages in Rasau Jaya District. The results of this study are in the form of a website-based elementary school sanitation infrastructure database which can be viewed on the website www.sigsanitasikuburaya.com. On the website, data can be seen including the availability of handwashing facilities, latrine facilities, clean water facilities, menstrual facilities, waste management facilities, and drainage facilities.
\end{abstract}

Keywords: Sanitation, Observations, Database, Website, Kubu Raya

\begin{abstract}
Abstrak
Penyusunan basis data infrastruktur sanitasi sekolah dasar negeri di Kecamatan Rasau Jaya didasari oleh Peraturan Menteri Pendidikan tahun 2007 tentang standar sarana dan prasarana sekolah dasar negeri di Indonesia. Selain itu, penelitian ini juga merupakan upaya mendukung program satu data Kabupaten Kubu Raya yang memiliki tujuan membantu pemerintah kabupaten dalam perencanaan program kabupaten agar dapat terimplementasi secara baik dan akurat di bidang infrastruktur sanitasi sekolah dasar negeri. Pada penelitian ini dilakukan observasi langsung ke lokasi serta melakukan wawancara terkait dengan ketersediaan infrastruktur sanitasi sekolah dasar. Jumlah sekolah dasar negeri yang termasuk dalam wilayah penelitian yaitu sebanyak 18 SD Negeri yang tersebar pada 6 desa di Kecamatan Rasau Jaya. Hasil dari penelitian ini berupa basis data infrastruktur sanitasi sekolah dasar negeri berbasis website yang dapat di akses melaui URL www.sigsanitasikuburaya.com. Pada website tersebut, menampilkan data terkait dengan basis data fasilitas cuci tangan, fasilitas jamban, fasilitas air bersih, fasilitas menstruasi, fasilitas pengelolaan sampah dan fasilitas drainase.

Kata Kunci: Sanitasi, Observasi, Basis data, Website, Kubu Raya

\section{Pendahuluan}

Infrastruktur sanitasi sekolah berhubungan erat dengan kualitas pendidikan pada sekolah tersebut. Semakin terjaga kebersihan di lingkungan sekolah, semakin besar pula dukungan terhadap kegiatan belajar dan mengajar serta akan meningkatkan kualitas pendidikan di sekolah. Beberapa faktor yang mempengaruhi kualitas lingkungan sekolah yaitu perilaku warga sekolah terkait dengan hidup bersih dan sehat serta ketersediaan infrastruktur sanitasi sekolah. Ketersediaan infrastruktur sanitasi sekolah dikatakan baik jika seluruh warga sekolah telah mengimplementasikan standar pola hidup bersih dan sehat (PHBS) dan sekolah tersebut memiliki infrastruktur sanitasi yang memadai. Infrastruktur sanitasi sekolah yang memadai seperti air bersih, jamban yang layak, saluran air limpasan hujan, tempat sampah dan tempat penampungan sementara, dan fasilitas untuk cuci tangan, serta fasilitas untuk mentruasi.
\end{abstract}


Kesehatan sekolah diselenggarakan untuk meningkatkan kemampuan hidup sehat peserta didik dalam lingkungan hidup sehat sehingga peserta didik dapat belajar, tumbuh, dan berkembang secara harmonis dan setinggi-tingginya menjadi sumber daya manusia yang berkualitas [1]. Lingkungan sekolah yang sehat akan mendukung tumbuh kembang perilaku hidup sehat serta berdampak bagi kesehatan jasmani maupun rohani dan terhindar dari pengaruh negatif yang dapat merusak kesehatan [2].

Prasarana adalah fasilitas dasar untuk menjalankan fungsi sekolah [3]. Sanitasi lingkungan sekolah merupakan salah satu infrastruktur penunjang aktivitas belajar namun akhir-akhir ini tidak terlalu diperhatikan secara merata. Kecamatan Rasau Jaya yang menjadi lokasi penelitian ini merupakan kecamatan jauh dari ibu kota provinsi dan ibu kota kabupaten oleh karena itu infrastruktur sanitasi di sekolah tidak merata hingga ke pelosok desa [4]. Namun tidak semua sekolah memperhatikan infrastruktur sanitasi sekolah, padahal infrastruktur sanitasi sekolah dapat berpengaruh terhadap kualitas pendidikan dan produktifitas belajar siswa. Akses air dasar dan sanitasi merupakan prasyarat untuk hak atas pendidikan dasar untuk anak sekolah [5].

Bercermin dari hasil statistik dari Kemendikbud bersama UNICEF tahun 2017 bahwa akses air tidak layak ataupun tidak memiliki akses air dasar yaitu 56,93\%, jamban tidak layak atau tidak memiliki jamban $14,74 \%$, tidak ada sarana fasilitas cuci tangan 50,20\% [6]. Kondisi sanitasi yang sangat memperhatinkan tersebut berhubungan dengan kualitas dan produktifitas siswa di sekolah dasar. Untuk menangani persoalan ini diperlukan kebijakan positif yang diatur oleh stakeholder tingkat nasional, kabupaten, lokal dan pihak sekolah dasar. Hal tersebut dilakukan untuk mendorong dan memfasilitasi pencapaian tingkat air, sanitasi dan kebersihan di sekolah [7].

Cuci tangan pakai sabun adalah perilaku cuci tangan dengan menggunakan air bersih yang mengalir dan sabun [8]. Penyakit diare paling besar berkontribusi pada tingkat kematian, kasus diare diperkirakan mencapai 4 miliar setiap tahun yang menimpa anak usia di bawah 5 tahun. Negara-negara berkembang berkontribusi menyumbang sekitar 19\% dari tingkat kematian [9]. Penyakit diare ini juga menyebabkan sekitar 300.000 balita meninggal setiap tahunnya di Asia Selatan [10].

Berdasarkan Permendiknas Nomor 24 Tahun 2007 tentang standar sarana dan prasarana untuk sekolah dasar menyatakan bahwa sebuah sekolah dasar sekurang-kurangnya memiliki prasarana yaitu ruang kelas, ruang perpustakaan, laboratorium IPA, ruang pimpinan, ruang guru, tempat ibadah, ruang UKS, jamban, gudang, ruang sirkulasi, dan tempat olahraga [3]. Di sekolah, pendidikan kebersihan dan sanitasi bertujuan mempromosikan praktik-praktik yang akan membantu siswa mencegah penyakit terkait sanitasi serta untuk mempromosikan perilaku sehat pada generasi orang dewasa di masa depan [11]. Selain itu, Fasilitas jamban di sekolah masih sering ditemukan dengan kondisi jamban yang gelap dan berbau [12].

Basis data bertujuan mengelola data menjadi sebuah informasi yang lebih berarti bagi pengguna yang menerimanya [13]. Penelitian ini bertujuan menyusun menyusun basis data infrastruktur sanitasi sekolah dasar negeri berbasis website sehingga membantu pemerintah Kabupaten Kubu Raya merencanakan program kabupaten agar dapat terimplementasi secara tepat dan akurat khusunya pada bidang infrastruktur sanitasi sekolah dasar negeri.

\section{Metodologi Penelitian}

\section{Gambar 1.}

Adapun metodologi yang dilakukan pada penelitian ini dapat lebih rinci dilihat pada bagan alir

\section{Metode Penyusunan Basis Data Infrastruktur Sanitasi Sekolah}

Penelitian ini dimulai dengan mengidentifikasi masalah kemudian studi literatur dan mengumpulkan data-data terkait antara lain data sekunder dari instansi terkait dan data primer berupa data yang pada saat survey. Pada tahap awal penelitian ini dilakukan identifikasi masalah berdasarkan data sekunder berupa profil sekolah dasar negeri dan data survey awal terkait dengan ketersediaan infrastruktur sanitasi sekolah.

Tinjauan pustaka

Tinjauan pustaka dilakukan dengan cara mengumpulkan referensi dan literatur yang berkaitan dengan hasil dari identifikasi masalah yang telah dilakukan. Sehingga teori-teori dari referensi tersebut dapat mendukung penelitian ini. 


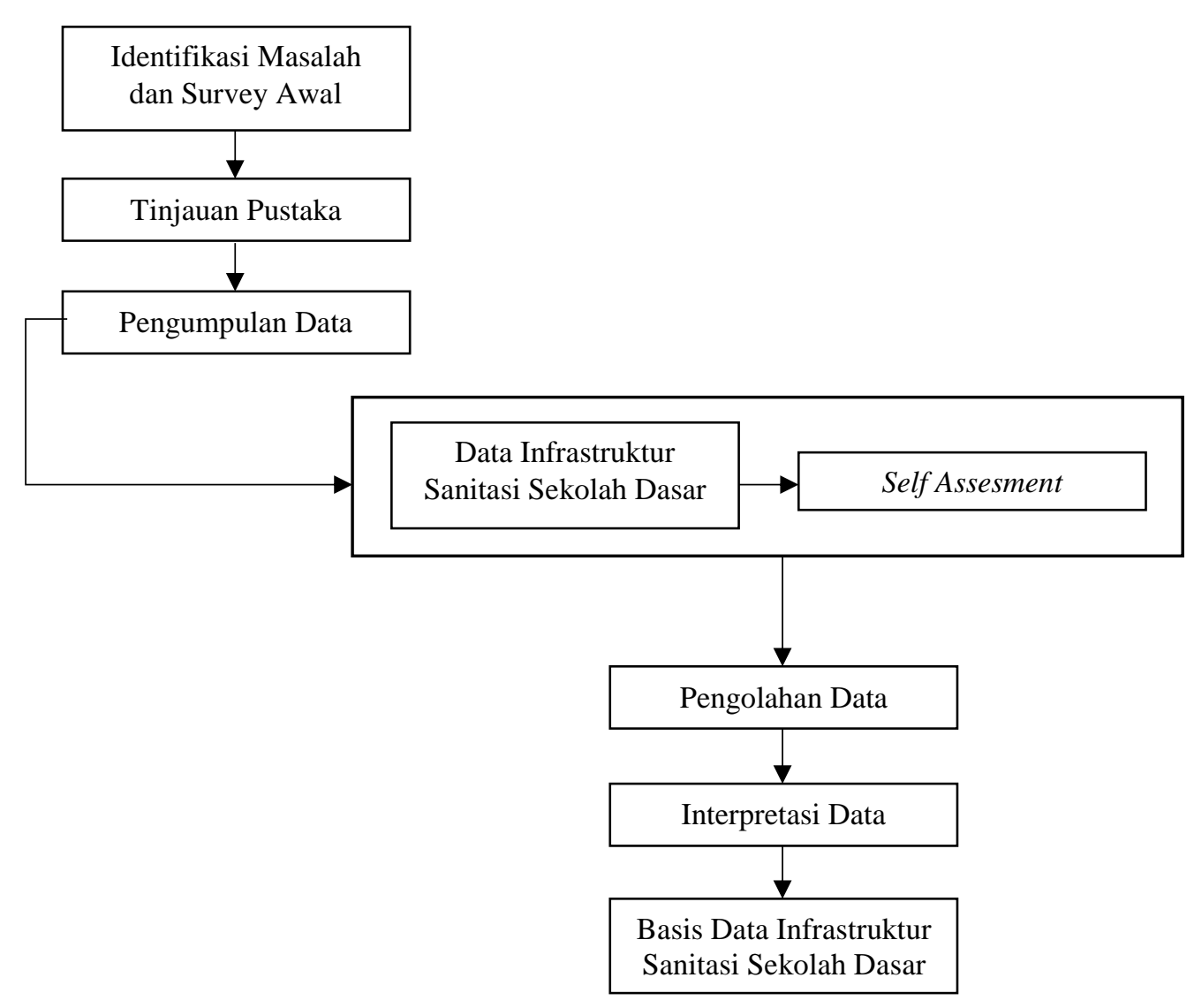

Gambar 1. Bagan alir penelitian

\section{Pengumpulan data primer}

Observasi lapangan dilakukan untuk mengetahui kondisi ketersediaan infrastruktur yang sebenarnya terkait dengan sanitasi sekolah. Penyebaran formulir self assesment [14] yang diisi oleh pihak sekolah dasar. Pemilihan sekolah dasar yang dilakukan observasi lapangan dan pengisian formulir self assement mengacu kepada sekolah dasar negeri yang berada di wilayah penelitian yaitu sebanyak 18 sekolah dasar negeri di Kecamatan Rasau Jaya, Kabupaten Kubu Raya.

Pengolahan data

Setelah dilakukan pengambilan data di lapangan, tahap selanjutnya yaitu pengolahan data untuk pengembangan sistem. Metode pengembangan sistem yang digunakan adalah metode waterfall yang secara keseluruhan memiliki tahapan-tahapan yang dilaksanakan secara berurutan (sequential), yaitu antara lain [15]:

Tahapan requirement analysis, pada tahapan ini yang dilakukan oleh pengembang sistem adalah melakukan analisis terhadap semua data yang sudah dikumpulkan untuk dipilah, dikelompokkan dan kemudian menentukan kebutuhan user terhadap sistem dan kebutuhan teknis sistem itu sendiri.

Tahapan system design, pada tahapan ini pengembang sistem merancang sistem secara terstruktur dan bertahap sesuai dengan hasil requirement analysis di atas. Rancangan dapat berupa business rules yang baru atau yang sudah disempurnakan, program flow chart, data flow diagram, UML Diagram, spesifikasi file dan database. Termasuk di dalam tahapan ini adalah menentukan bahasa pemrograman beserta perangkat lunak pendukungnya seperti database server, application server, mock-up utilities dan sebagainya.

Tahapan implementation, pada tahapan ini dilakukan implementasi dari desain-desain yang sudah dibuat pada tahap sebelumnya. Baik pembangunan perangkat lunak aplikasi baru atau pembenahan 
manajemen, aturan bisnis (business rules), rekrutmen operator dan hal-hal lain yang dispesifikasikan di dalam dokumen desain sistem.

Tahapan testing, pada tahapan ini dilakukan uji coba terhadap sistem yang baru. Uji coba dapat dilakukan dengan tiga cara yaitu:

1. Secara langsung menggantikan sistem lama.

2. Secara bertahap melakukan uji coba per bagian.

3. Secara paralel, dimana sistem baru berjalan bersama sistem lama yang masih operasional. Hal ini berguna agar dapat dilakukan komparasi hasil antara sistem baru dan lama.

Selama melakukan uji coba, pengembang sistem harus memantau dan bekerja sama dengan operator sistem agar dapat diketahui dengan segera kendala atau permasalahan yang muncul pada saat sistem digunakan. Dengan demikian, semua permasalahan dapat segera diatasi dan pada akhirnya akan menghasilkan sistem yang kokoh (robust) dan dapat diandalkan (reliable).

Tahapan deployment, tahapan ini menandakan sistem telah siap digunakan karena telah melalui tahapan uji coba dan penyempurnaan. Pada tahapan ini, sistem lama telah digantikan sepenuhnya oleh sistem baru.

Tahapan maintenance, pada tahapan ini pengembang sistem melakukan perbaikan, penambahan fitur ataupun penyempurnaan modul sistem berdasarkan perkembangan kebutuhan pengguna. Dengan munculnya kebutuhan baru dari pengguna pada tahapan ini maka siklus waterfall akan kembali ke tahapan requirement analysis.

\section{Hasil dan Pembahasan}

\section{Data Infrastruktur Jamban dan Data Air Besih}

Hasil observasi terkait dengan data jamban dan data air bersih dapat dilihat pada Gambar 2. Gambar tersebut merupakan rekapitulasi data jumlah jamban siswa dan data jumlah jamban guru yang dimiliki oleh SD Negeri di Kecamatan Rasau Jaya serta menampilkan data jumlah penampungan air bersih.

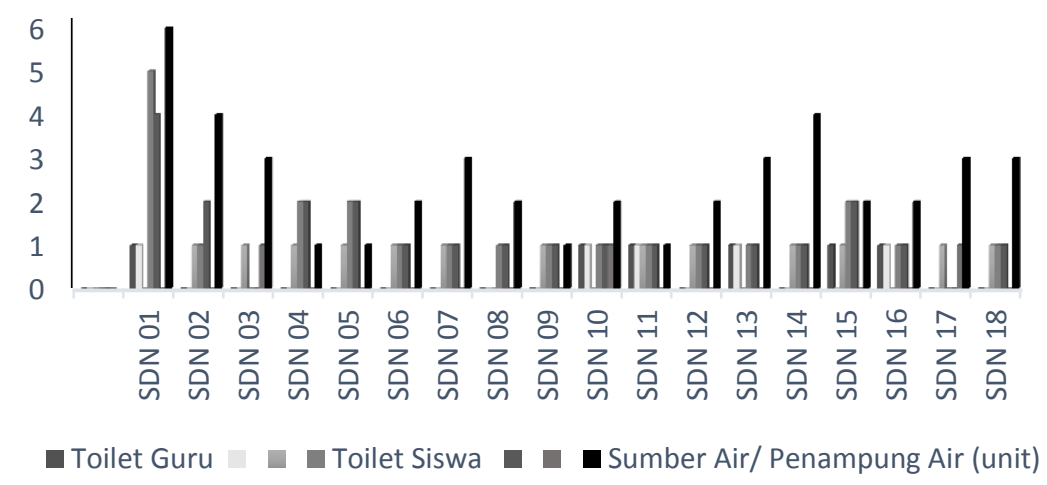

Gambar 2. Rekapitulasi data infrastruktur jamban dan data sumber air bersih Sekolah Dasar Negeri Di Kecamatan Rasau Jaya (Survey, 2019)

Berdasarkan observasi pada Gambar 3. terkait dengan data infrastruktur jamban dan data sumber air bersih di sekolah dasar negeri di Kecamatan Rasau Jaya menyatakan bahwa masih ada sekolah dasar negeri yang tidak memiliki kecukupan jamban sehingga jamban tersebut digunakan tidak terpisah (TT) untuk siswa laki-laki dan perempuan. Sekolah yang masih memiliki jamban yang tidak terpisah antara lain: SD Negeri 03 Rasau Jaya, SD Negeri 10 Rasau Jaya dan SD Negeri 17 Rasau Jaya. Selain itu, berdasarkan hasil obeservasi di lapangan ditemukan hanya 5 sekolah dasar negeri yang telah memisahkan penggunaan jamban untuk guru laki-laki dan guru perempuan yaitu SD Negeri 01 Rasau Jaya, SD Negeri 10 Rasau Jaya, SD Negeri 11 Rasau Jaya, SD Negeri 13 Rasau Jaya dan SD Negeri 16 Rasau Jaya. 


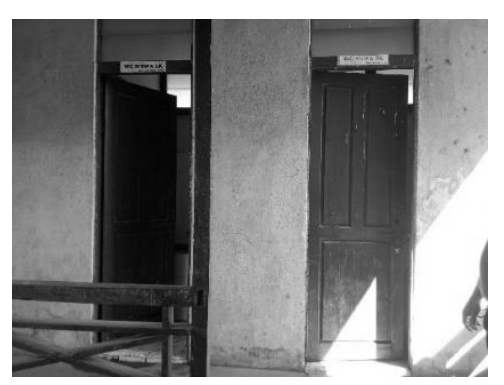

(a)

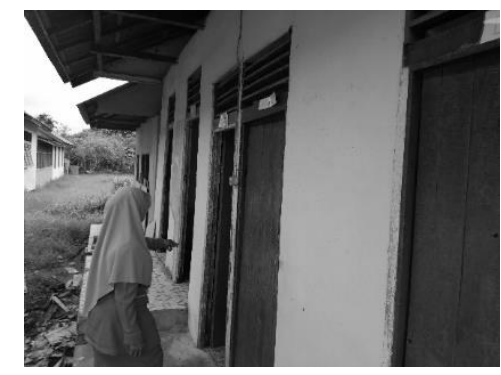

(b)

Gambar 3. (a) Kondisi jamban di SD Negeri 16 Rasau Jaya, (b) Kondisi jamban di SD Negeri 02 Rasau Jaya

Selain itu, terkait dengan data sumber air bersih pada setiap sekolah dasar negeri di Kecamatan Rasau Jaya. Berdasarkan hasil observasi di lapangan bahwa sumber air bersih dari setiap sekolah menggunakan air hujan dan air sumur/parit yang ditampung dalam tandon air untuk keperluan di jamban seperti Gambar 4.

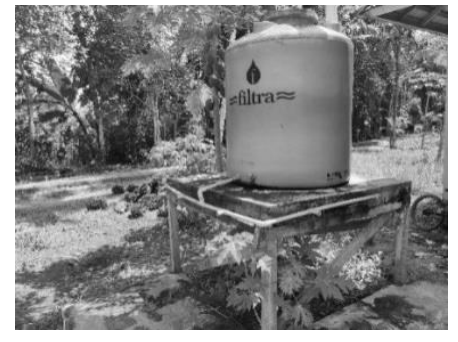

(a)

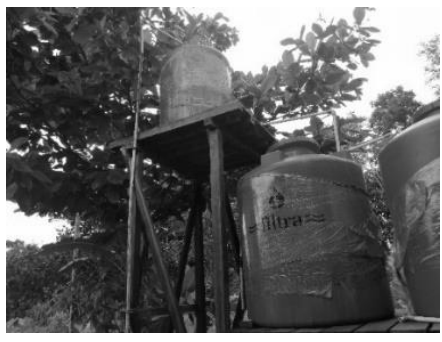

(b)

Gambar 4. (a) Penampungan air bersih SD Negeri, (b) Penampungan air bersih SD Negeri 13 06 Rasau Jaya

\section{Data Infrastruktur Fasilitas Cuci Tangan dan Fasilitas Menstruasi}

Hasil observasi terkait dengan data fasilitas tempat cuci tangan dan fasilitas menstruasi dapat dilihat pada Gambar 5. Gambar tersebut merupakan rekapitulasi data jumlah fasilitas cuci tangan yang dimiliki oleh SD Negeri di Kecamatan Rasau Jaya serta menampilkan data fasilitas menstruasi.

Berdasarkan hasil observasi terkait dengan data fasilitas cuci tangan bahwa hanya 5 sekolah dasar negeri yang menyediakan fasilitas cuci tangan di dalam kelas dan 13 sekolah dasar tidak menyediakan fasilitas cuci tangan di dalam kelas.

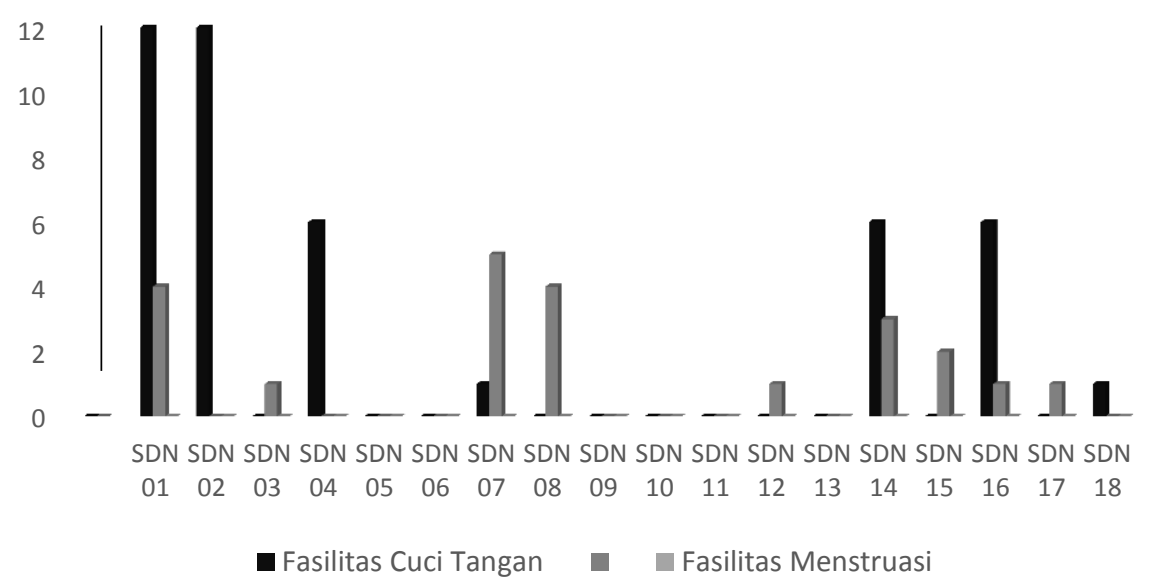

Gambar 5. Rekapitulasi data fasilitas cuci tangan dan fasilitas menstruasi sekolah dasar negeri di Kecamatan Rasau Jaya (Survey, 2019) 
Selain itu ada 6 sekolah dasar negeri yang tidak menyediakan fasilitas cuci tangan di dalam kelas maupun di luar kelas. Terkait dengan fasilitas menstruasi yaitu tempat sampah khusus dan gantungan serta cermin tidak ada sekolah dasar negeri yang menyediakan fasilitas tersebut seperti tampak dalam Gambar 6 dan Gambar 7.

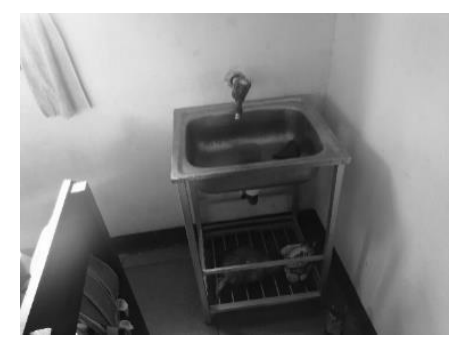

(a)

Gambar 6. (a) Tempat cuci tangan di dalam kelas, SD Negeri 01 Rasau Jaya

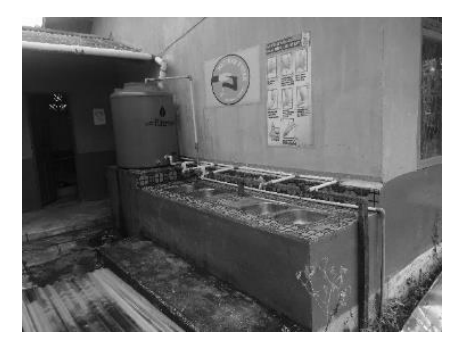

(a)

Gambar 7. (a) Tempat cuci tangan di luar kelas, SD Negeri 01 Rasau Jaya

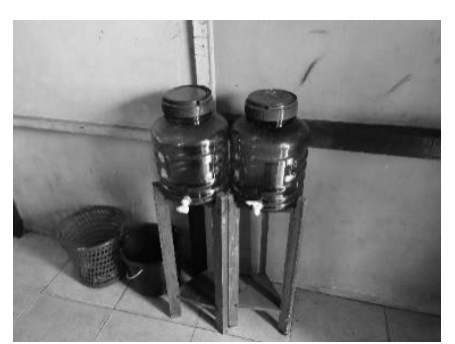

(b)

(b) Tempat cuci tangan di dalam kelas SD Negeri 02 Rasau Jaya

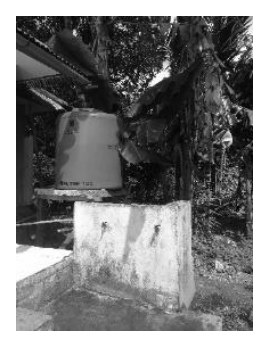

(b)

(b) Tempat cuci tangan di luar kelas SD Negeri 14 Rasau Jaya

\section{Data Infrastruktur Pengelolaan Sampah dan Saluran Drainase}

Hasil observasi terkait dengan data infrastruktur pengelolaan sampah dan saluran air/drainase dapat dilihat pada Tabel 3. Tabel tersebut merupakan rekapitulasi data jumlah tempat sampah dan TPS sampah serta data saluran air/drainase yang dimiliki oleh SD Negeri di Kecamatan Rasau Jaya.

Tabel 3. Rekapitulasi data infrastruktur pengelolaan sampah dan saluran air/drainase sekolah dasar negeri di Kecamatan Rasau Jaya

\begin{tabular}{cccccl}
\hline & & \multicolumn{3}{c}{ Pengelolaan Sampah } & \\
\cline { 3 - 5 } No & Nama Sekolah & $\begin{array}{c}\text { di } \\
\text { dalam } \\
\text { Kelas }\end{array}$ & $\begin{array}{c}\text { di } \\
\text { luar } \\
\text { kelas }\end{array}$ & $\begin{array}{c}\text { TPS } \\
\text { Sampah }\end{array}$ & Sir/Dran \\
& & 0 & 12 & 3 & Tersedia \\
\hline 1 & SDN 01 Rasau Jaya & 0 & 12 & 1 & Tersedia \\
2 & SDN 02 Rasau Jaya & 0 & 1 & 1 & Tersedia \\
3 & SDN 03 Rasau Jaya & 5 & 6 & 1 & Tidak \\
4 & SDN 04 Rasau Jaya & 0 & 2 & 2 & Tersedia \\
5 & SDN 05 Rasau Jaya & 12 & 2 & 2 & Tidak \\
6 & SDN 06 Rasau Jaya & 0 & 3 & 1 & Tidak \\
7 & SDN 07 Rasau Jaya & 6 & 6 & 1 & Tidak \\
8 & SDN 08 Rasau Jaya & 6 & 0 & 1 & Tidak \\
9 & SDN 09 Rasau Jaya & 6 & 2 & 2 & Tersedia \\
10 & SDN 10 Rasau Jaya & 9 & 3 & 1 & Tersedia \\
11 & SDN 11 Rasau Jaya & 0 & 8 & & \\
\hline
\end{tabular}




\begin{tabular}{llllll}
\hline 12 & SDN 12 Rasau Jaya & 6 & 1 & 1 & Tersedia \\
13 & SDN 13 Rasau Jaya & 0 & 8 & 1 & Tersedia \\
14 & SDN 14 Rasau Jaya & 8 & 8 & 1 & Tersedia \\
15 & SDN 15 Rasau Jaya & 0 & 3 & 2 & Tidak \\
16 & SDN 16 Rasau Jaya & 6 & 6 & 1 & Tidak \\
17 & SDN 17 Rasau Jaya & 5 & 0 & 1 & Tersedia \\
18 & SDN 18 Rasau Jaya & 5 & 3 & 1 & Tidak \\
\hline
\end{tabular}

Sumber: Hasil analisa (2019)

Berdasarkan hasil observasi terkait dengan fasilitas pengelolaan persampahan setiap sekolah dasar negeri di Kecamatan Rasau Jaya telah memiliki tempat sampah, yang diletakan dalam kelas ataupun luar kelas serta setiap sekolah dasar negeri juga telah memiliki TPS sampah guna penanganan sampah. Penanganan sampah di sekolah dasar negeri dengan cara membakar sampah di tempat yang telah disediakan. Selain itu berdasarkan hasil observasi terkait dengan saluran air/drainase ada sebanyak 8 sekolah dasar negeri di Kecamatan Rasau Jaya tidak tersedia saluran air. Posisi letak tong sampah dapat dilihat pada Gambar 8-11.

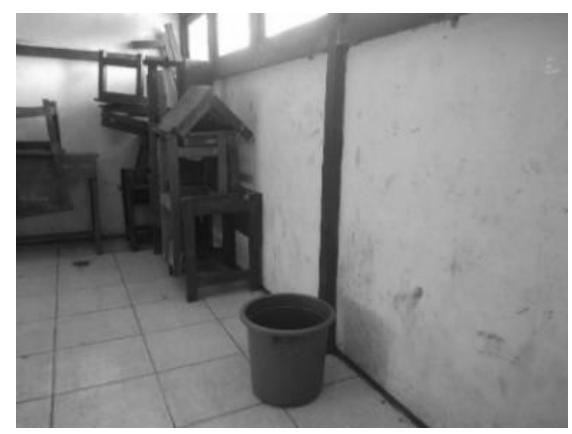

(a)

Gambar 8. (a) Tempat sampah di dalam kelas SD Negeri 17 Rasau Jaya,

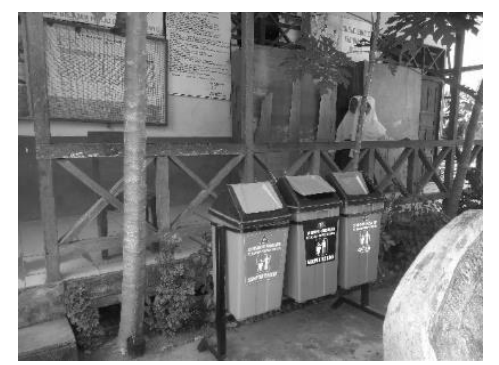

(a)

Gambar 9. (a) Tempat sampah di luar kelas, SD Negeri 03 Rasau Jaya

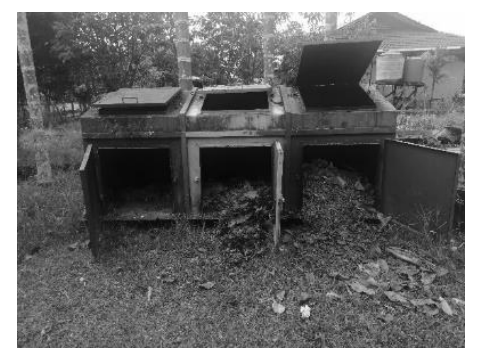

(a)

Gambar 10. (a) TPS Sampah SD Negeri 01, Rasau Jaya

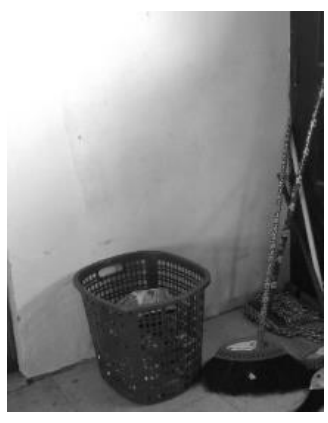

(b)

(b) Tempat sampah di dalam kelas SD Negeri 18 Rasau Jaya

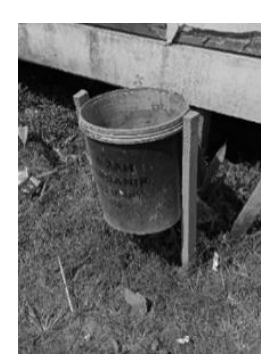

(b)

(b) Tempat sampah di luar kelas SD Negeri 09 Rasau Jaya

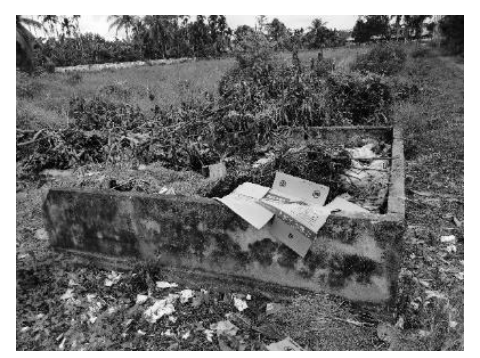

(b)

(b) TPS Sampah SD Negeri 02 Rasau Jaya 


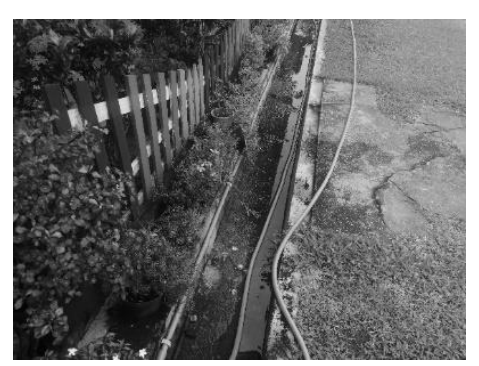

(a)

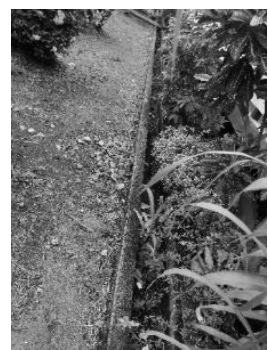

(b)

Gambar 11. (a) Saluran Air SD Negeri 01 Rasau Jaya,

(b) Saluran Air SD Negeri 02 Rasau Jaya

\section{Penyusunan Basis Data Berbasis Website}

Dalam penelitian ini juga menggunakan sistem informasi geografis untuk menampilkan hasil analisis kebutuhan infrastruktur sanitasi pada 18 sekolah dasar negeri di Kecamatan Rasau Jaya yang merupakan wilayah penelitian. Data-data yang dapat dilihat pada website tersebut seperti pada Tabel 4.

Tabel 4. Data-data yang dapat diakses pada website

\begin{tabular}{cl}
\hline No & Data yang ditampilkan pada website \\
\hline 1. & Lokasi Sekolah Dasar Negeri \\
2. & Profil Sekolah Dasar Negeri \\
3. & Ketersediaan Infrastruktur Sanitasi Sekolah Dasar \\
4. & Kondisi Infrastruktur Sanitasi Sekolah Dasar \\
5. & Kebutuhan Infrastruktur Sanitasi \\
6. & Peraturan yang Terkait dengan Sanitasi Sekolah Dasar \\
\hline
\end{tabular}

\section{Panduan Penggunaan Website}

Halaman Log In, halaman ini dapat diakses melalui URL http://sigsanitasikuburaya.com/dashboard dan merupakan halaman pertama yang ditemui sebelum dapat mengakses halaman administrator Basis Data Infrastruktur Sanitasi Sekolah Dasar Negeri Kec. Rasau Jaya. Terdapat dua level pengguna yang dapat mengakses sistem ini, yaitu level administrator dan operator. Khusus untuk level operator diperuntukkan bagi operator sekolah agar dapat memperbaharui basis data infrastruktur sanitasi sekolahnya masing-masing. Untuk dapat melanjutkan ke halaman administrator, pengguna memerlukan username dan password yang sudah divalidasi dan didaftarkan oleh administrator ke dalam sistem ini.

\section{Halaman Basis Data Desa}

Halaman ini berfungsi untuk mengelola data desa yang ada di Kecamatan Rasau Jaya Kab. Kubu Raya. Data Desa ini berelasi ke data sekolah sehingga dapat dilakukan pencarian per desa.

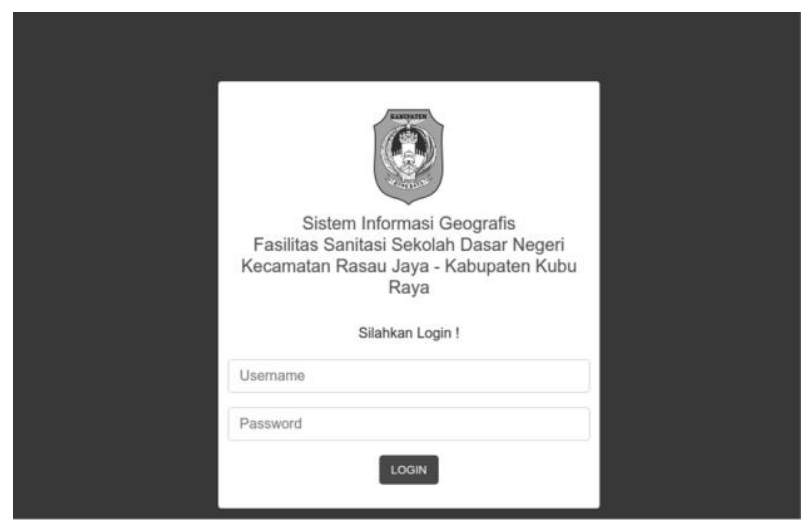

Gambar 12. Halaman Login 


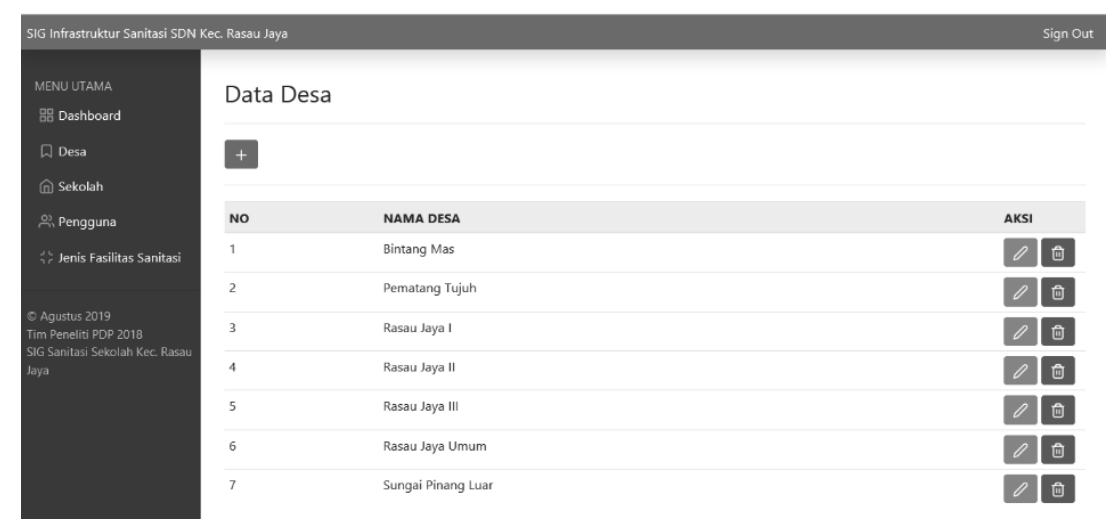

Gambar 13. Halaman administrasi desa

\section{Halaman Basis Data Jenis Fasilitas}

Halaman ini berfungsi untuk mengelola data jenis fasilitas sanitasi, data ini diperlukan dalam pengelolaan data fasilitas sanitasi per sekolah yang nantinya dapat diakses melalui menu data sekolah.

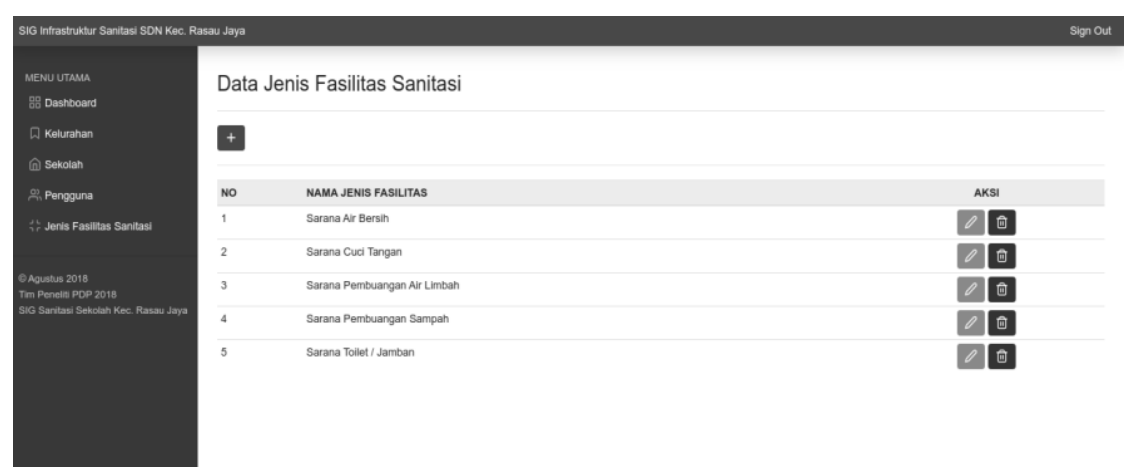

Gambar 14. Halaman data jenis fasilitas sanitasi

\section{Halaman Basis Data Sekolah}

Halaman ini merupakan inti dari basis data infrastruktur Sanitasi Sekolah, data sekolah yang dapat direkam melalui halaman ini antara lain adalah nama desa lokasi sekolah tersebut, nama sekolah, alamat sekolah, nama kepala sekolah, NISN, NPSN, koordinat GPS sekolah, jumlah ruang kelas, jumlah siswa lakilaki, jumlah siswa perempuan, jumlah guru \& staff pria dan jumlah guru \& staff wanita.

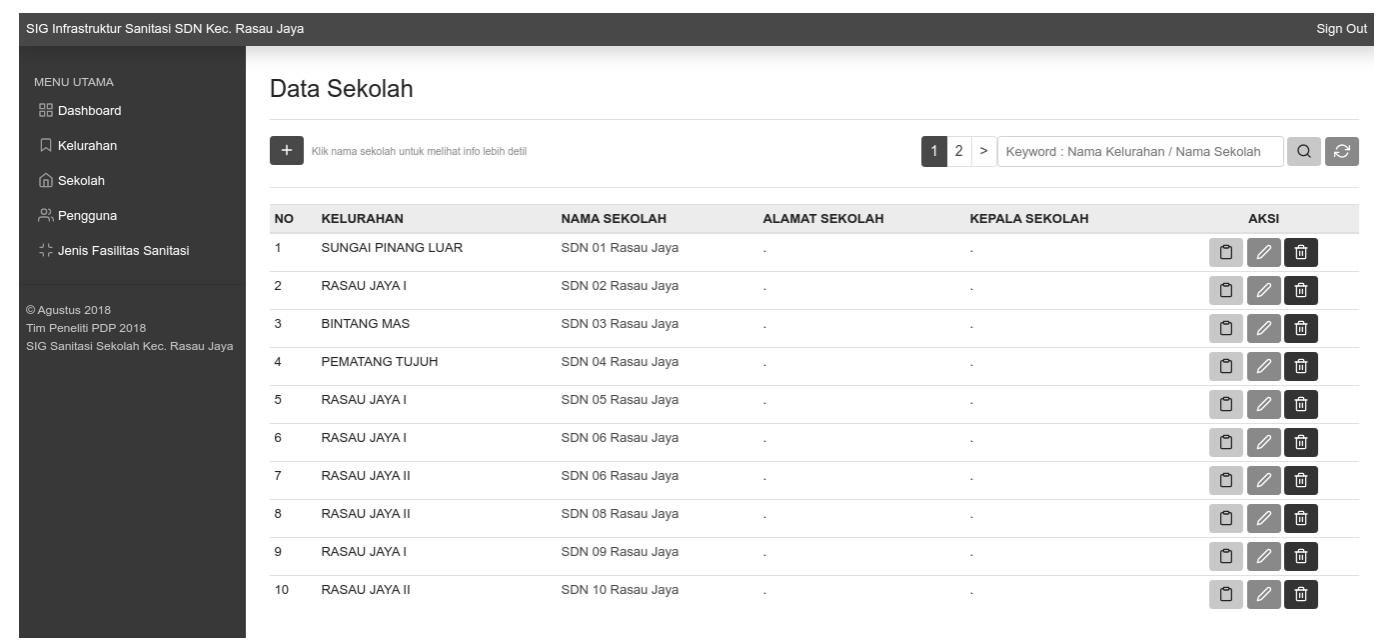

Gambar 15. Halaman data sekolah negeri di Kecamatan Rasau Jaya 


\section{Halaman Administrasi Fasilitas Sanitasi}

Halaman ini merupakan bagian dari halaman administrasi data sekolah yang dapat diakses melalui tombol yang dilingkari seperti yang terlihat pada Gambar 16.

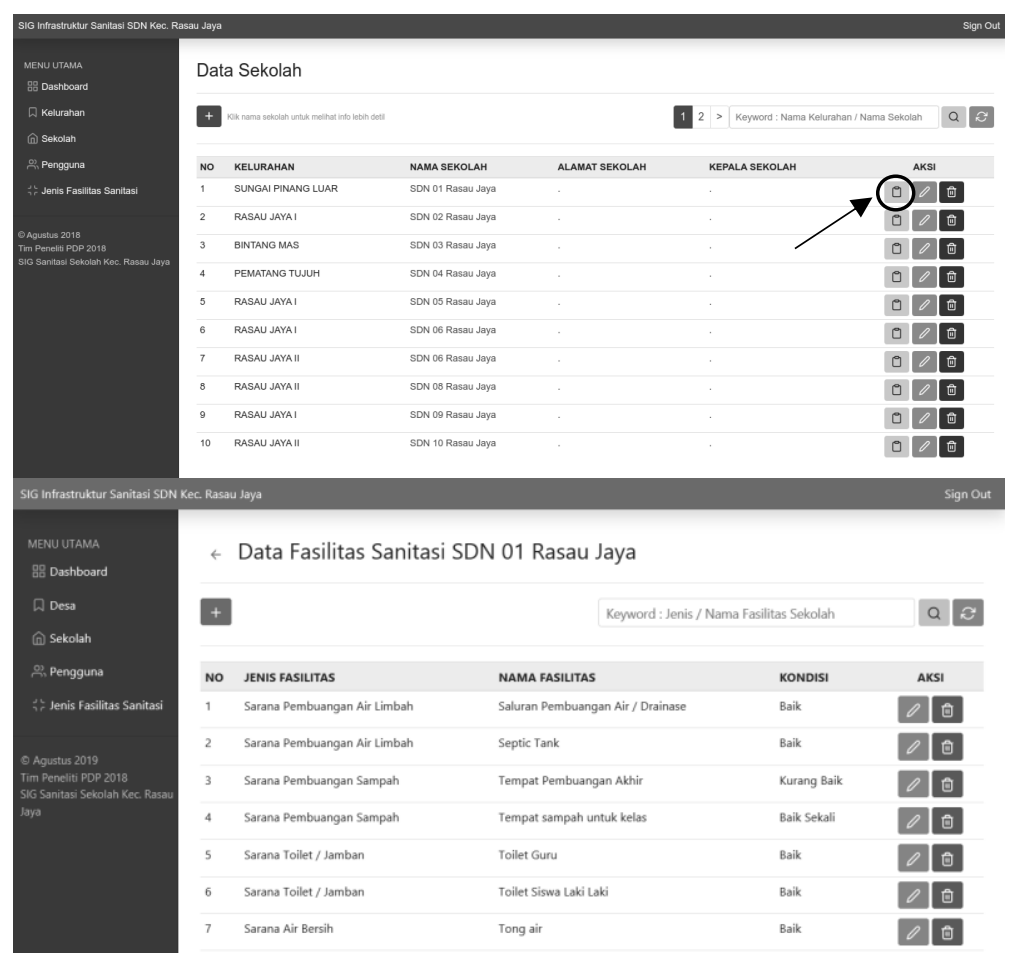

Gambar 16. Halaman administrasi fasilitas sanitasi

Pada halaman administrasi data fasilitas sanitasi ini data yang dapat disajikan adalah data jenis fasilitas, nama fasilitas, jumlah fasilitas, kondisi fasilitas dan foto-foto fasilitas yang bersangkutan.

Halaman Administrasi Data Pengguna

Halaman ini digunakan untuk mengelola data administrasi pengguna Basis Data Infrastruktur Sanitasi Sekolah ini, disini administrator dapat mengatur hak akses menu dan login pengguna berdasarkan kebutuhan.

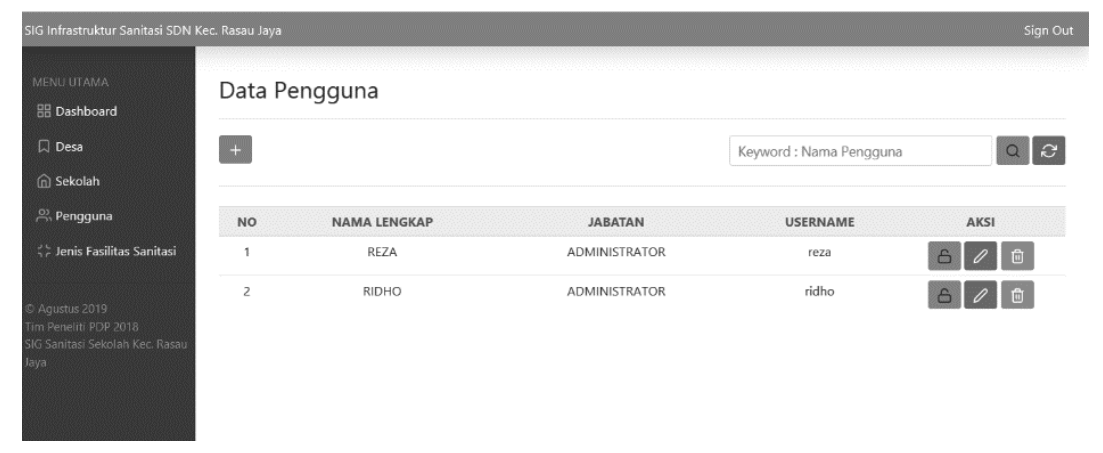

Gambar 17. Halaman administrasi data pengguna

\section{Kesimpulan}

Pada saat ini ketersediaan infrastruktur sanitasi sekolah dasar negeri di Kecamatan Rasau Jaya Kabupaten Kubu Raya yang dinilai dari beberapa komponen ketersediaan infrastruktur sanitasi yang masih memiliki kategori buruk sampai dengan sedang dan hanya 2 komponen penilaian yang termasuk dalam kategori baik. Data tersebut dapat diakses melalui URL http://sigsanitasikuburaya.com/dashboard. Melalui basis data infrastruktur sanitasi sekolah dapat direncanakan program penyelesaian ketersediaan infrastruktur sanitasi sekolah yang mendesak seperti ketersediaan fasilitas cuci tangan dan fasilitas menstruasi. 


\section{Daftar Pustaka}

[1] Undang-undang Nomor 36 Tahun 2009 tentang Kesehatan. Jakarta.

[2] Dina Andriani. 2013. Studi tentang Sanitasi Lingkungan SD Negeri di Kecamatan Sungai Beremas Kabupaten Pasaman Barat. Jurnal. Sumatera Barat: Geografi STKIP PGRI.

[3] Peraturan Menteri Pendidikan Nasional Nomor 24 Tahun 2007 Standar Sarana dan Prasarana Sekolah Dasar/Madrasah Ibtidaiyah, Sekolah Menegah Pertama/Madrasah Tsanawiyah dan Sekolah Menengah Atas/Madrasah Aliyah. Jakarta.

[4] Laporan Studi EHRA, 2018. Kelompok Kerja Air Minum dan Sanitasi, Kabupaten Kubu Raya.

[5] Adams, J, Bartram, J, Chartier, Y \& Sims, 2009. Water, sanitation and hygiene standards for schools in low-cost settings, Geneva.

[6] Pusat Data \& Statistik Pendidikan dan Kebudayaan, 2017. Profil Sanitasi Sekolah 2017. Jakarta.

[7] Burgers, L, 2000, Background and rationale for school sanitation and hygiene education, New York.

[8] Peraturan Menteri Kesehatan Nomor 3 tahun 2014 Sanitasi Total Berbasis Masyarakat. Jakarta

[9] Freeman, et al., 2014. Systematic Review: Hygiene and health: Systematic review of handwashing practices worldwide and update of health effects, Tropical Medicine and International Health, Vol 19 No. 8 p906-916.

[10] WHO, 2008, tingkat kematian balita

[11] O'Reily dkk. 2006: The impact of a school-based safe water and hygiene programme on knowledge and practices of students and their parents: Nyanza Province, Western Kenya. Epidemiology and Infection, 136(1), pp. 80-91.

[12] Asosiasi Toilet Indonesia, 2010.

[13] Jogiyanto, H.M., 2005. Analisa dan Desain Sistem Informasi: Pendekatan Terstruktur Teori dan Praktik Aplikasi Bisnis. Yogyakarta: Andi.

[14] Kelompok Kerja Pembangunan Perumahan, Permukiman, Air Minum dan Sanitasi (Pokja PPAS) Nasional.2018. Pedoman Penyusunan Strategi Sanitasi Kabupaten/Kota. Jakarta.

[15] Pressman, Roger S. 2012. Rekayasa Perangkat Lunak - Buku Satu, Pendekatan Praktisi (Edisi 7). Yogyakarta: Andi 